\title{
DESEMPENHO PRODUTIVO DE GENÓTIPOS DE MILHO SOB DIFERENTES ARRANJOS ESPACIAIS PARA A PRODUÇÃO DE SILAGEM
}

\author{
Antônio Barbosa da Silva Júnior ${ }^{1 *}$; Paulo Vanderlei Ferreira; Jorge Luiz Xavier Lins Cunha; Rosa \\ Cavalcante Lira²; Islan Diego Espindula de Carvalho4.
}

\begin{abstract}
${ }^{1} \mathrm{Eng}^{\circ}$. Agr. MSc. e Doutorando em Agronomia, Centro de Ciências Agrárias (CECA), Universidade Federal de Alagoas (UFAL), BR 104 Norte, Km 85, Rio Largo, AL. CEP 57.000-100.

2Professor, Centro de Ciências Agrárias (CECA), Universidade Federal de Alagoas (UFAL), BR 104 Norte, Km 85, Rio Largo, AL. CEP 57.000-100. ${ }^{3}$ Pesquisador, Centro de Ciências Agrárias (CECA), Universidade Federal de Alagoas (UFAL), BR 104 Norte, Km 85, Rio Largo, AL. CEP 57.000-100.

${ }^{4}$ Doutorando em Genética e Melhoramento de Plantas (UFRPE), Centro de Ciências Agrárias (CECA), Universidade Federal de Alagoas (UFAL), BR 104 Norte, Km 85, Rio Largo, AL. CEP 57.000-100.
\end{abstract}

*Autor para correspondência: Antônio Barbosa da Silva Júnior, Antonio.barbosa@ceca.ufal.br.

RESUMO: O objetivo do presente trabalho foi avaliar o desempenho de genótipos de milho em diferentes arranjos espaciais para a produção de silagem. Foram avaliados oito genótipos de milho, Alagoano, Branca, Nordestino, São Luiz, Viçosense, BR 106, AL Bandeirante e Jabotão. Foram utilizados dois arranjos espaciais: 0,6 x 0,2 m (166.666 plantas.ha- ${ }^{-1}$ e e $0,8 \times 0,2 \mathrm{~m}$ (125.000 plantas.ha $\left.^{-1}\right)$, com 10 plantas por metro linear. No Experimento 1, utilizou-se o delineamento experimental em blocos casualizados, no esquema fatorial de $8 \times 2$, com três repetições, totalizando 48 parcelas experimentais. Cada parcela experimental foi constituída de 4 fileiras de $6 \mathrm{~m}$ de comprimento com 2 plantas por cova. No Experimento 2 foram utilizadas as plantas colhidas no experimento 1 , em que utilizou-se o delineamento inteiramente casualizado, no esquema fatorial de $8 \times 2$, com três repetições, totalizando 48 parcelas experimentais. Cada parcela experimental foi constituída de um cano de PVC de 0,50 $\mathrm{m}$ de comprimento por $0,10 \mathrm{~m}$ de diâmetro, com volume de $0,157 \mathrm{~m}^{3}$. Foram avaliadas variáveis de interesse agronômico para a produção de silagem. Quanto à variável RMVPI, o genótipo Branca e a variedade crioula Jabotão apresentaram os maiores rendimentos de matéria verde da planta inteira e diferiram estatisticamente da variedade comercial BR 106, enquanto que os demais genótipos tiveram um comportamento intermediário entre estes. $O$ aumento da densidade populacional, através do arranjo espacial, proporciona maior matéria verde da planta inteira, sem alterar as demais características agronômicas. As variedades de milho Alagoano, Branca, Nordestino, São Luiz, Viçosense, BR 106 e AL Bandeirante apresentaram características favoráveis à produção de silagem. Na produção de milho para silagem de alta qualidade, a variedade Branca é a mais indicada por ter um alto rendimento de matéria verde da planta inteira, em torno de 71 toneladas de forragem por hectare, uma alta contribuição de espigas, acima de 50\%, e uma baixa contribuição de colmos, em torno $33 \%$.

PALAVRAS-CHAVES: Zea mays, silagem, populações, densidade populacional

\section{PRODUCTIVE PERFORMANCE OF CORN GENOTYPES UNDER DIFFERENT SPACE ARRANGEMENTS FOR THE PRODUCTION OF SILAGE}

ABSTRACT: The objective of the present work was to evaluate the performance of maize genotypes in different spatial arrangements for silage production. Eight maize genotypes, Alagoano, Branca, Nordestino, São Luiz, Viçosense, BR 106, AL Bandeirante and Jabotão were evaluated. Two spatial arrangements were used: $0.6 \mathrm{x}$ $0.2 \mathrm{~m}$ (166.666 plants.ha- $\left.{ }^{-1}\right)$ and $0.8 \times 0.2 \mathrm{~m}\left(125,000\right.$ plants. ha $\left.^{-1}\right)$, with 10 plants per linear meter. In Experiment 1 , the experimental design was a randomized block design, in the $8 \times 2$ factorial scheme, with three replications, totaling 48 experimental plots. Each experimental plot consisted of 4 rows of $6 \mathrm{~m}$ in length with 2 plants per hole. In Experiment 2 the plants harvested in experiment 1 were used, in which the completely randomized design was used in the $8 \times 2$ factorial scheme, with three replications, totaling 48 experimental plots. Each experimental plot was composed of a PVC pipe $0.50 \mathrm{~m}$ long by $0.10 \mathrm{~m}$ in diameter, with a volume of $0.157 \mathrm{~m}^{3}$. Variables of agronomic interest were evaluated for silage production. Regarding the RMVPI variable, the genotype Branca and the Jabotão 
creole variety had the highest yields of green matter of the whole plant and differed statistically from the commercial variety BR 106, while the other genotypes had an intermediary behavior among them. The increase of the population density through the spatial arrangement, provides greater green matter of the whole plant, without altering the other agronomic characteristics. The corn varieties Alagoano, Branca, Nordestino, São Luiz, Viçosense, BR 106 and AL Bandeirante presented favorable characteristics for silage production. In the production of maize for high quality silage, the Branca variety is best indicated because it has a high yield of green matter of the whole plant, around 71 tons of forage per hectare, a high contribution of spikes, over $50 \%$, And a low contribution of stems, around $33 \%$.

KEYWORDS: Zea mays, silage, populations, population density

\section{INTRODUÇÃO}

A silagem de milho constitui uma das principais fontes de volumoso com bons valores nutritivos, sendo 0 volumoso que apresenta maior capacidade de aumentar a produção de ruminantes e diminuir o tempo para 0 abate, além da boa aceitabilidade pelos animais, e com altos rendimentos por área, tornandose um alimento ainda mais atrativo para o produtor, possuindo facilidade do manuseio de seu plantio ao armazenamento (Neumann et al., 2004).

A alta produção de silagem de boa qualidade depende das características do genótipo utilizado, da técnica utilizada no preparo da silagem, da estrutura de armazenamento, entre outros fatores. 0 genótipo influencia na qualidade da silagem desde suas características morfológicas até sua composição química, então a depender das partes do vegetal utilizadas, mudará completamente seu valor nutritivo, que no caso da planta de milho é convencional a utilização da planta inteira, porém em alguns casos a espiga é comercializada e a silagem é produzida apenas com a estrutura vegetativa (Costa et al., 2000; Deminicis et al., 2009).

A produtividade de silagem de milho é influenciada por diversos fatores bióticos, abióticos e de manejo, dentre esses a densidade populacional e o material genético utilizado são os principais, sendo recomendada uma densidade populacional maior do que para a produção de grãos, porém essa é muito influenciada pela responsividade dos genótipos que por sua vez pode alterar as qualidades da silagem (Modolo et al., 2010; Cardoso e Ribeiro, 2013).

0 arranjo de plantas pode ser alterado por meio de mudanças na população de plantas, no espaçamento entre linhas, na distribuição de plantas na linha. 0 melhor arranjo é aquele que proporciona uniformidade na distribuição de plantas, possibilitando melhor utilização dos fatores necessários para alcançar uma alta produtividade (Brachtvogel et al., 2012).
A densidade populacional utilizada para a produção de silagem varia de 70.000 a 120.000 plantas. ha-1 ${ }^{-1}$ sendo que o incremento dessa aumenta a produtividade de massa da silagem de acordo com 0 arranjo espacial, pois as maiores densidades promovem maior crescimento das plantas e em consequência maior produção de massa (Demétrio et al., 2008).

Aescolha da variedade de milho para a produção de silagem deve levar em consideração a capacidade de resposta produtiva do genótipo, vez que a competição em função das altas densidades populacionais exige dos genótipos maior capacidade competitiva, além das características qualitativas, tais como, ciclo, altura de plantas, maior contribuição de colmos e folhas na massa dentre outras (Mello et al., 2005).

Oobjetivo dessetrabalhofoiavaliaro desempenho produtivo de genótipos de milho sob diferentes arranjos espaciais para a produção de silagem.

\section{MATERIAL E MÉTODOS}

0 experimento1 foi conduzido na área experimental do Setor de Melhoramento Genético de Plantas do Centro de Ciências Agrárias da Universidade Federal de Alagoas (SMGP-CECA-UFAL), no município de Rio Largo-AL, localizada a $9^{\circ} 27^{\prime}$ de latitude sul e $35^{\circ} 27^{\prime}$ de longitude oeste e $127 \mathrm{~m}$ de altitude. Cujo clima é do tipo A's de Koppen (tropical quente e úmido com estações seca de primavera-verão e chuvosa de outono-inverno), com precipitações pluviométricas anuais variando de 1.500 a $2.000 \mathrm{~mm}$, temperatura média de $26^{\circ} \mathrm{C}$ e umidade relativa do ar de $80 \%$ (Souza et al., 2004), e solo classificado como Latossolo Amarelo Coeso argissolico, de textura franco arenosa (Santos etal., 2006). 0 Experimento 1 foi conduzido no período de dezembro de 2013 à abril de 2014 na área experimental do referido setor e o experimento 2 foi conduzido no período de abril à junho de 2014, no Laboratório do SMGP-CECA-UFAL.

Os experimentos avaliaram dois grupos de tratamentos: Grupo 1: Genótipos de Milho e Grupo 2: 
Arranjos Espaciais. No Grupo 1, foram avaliados oito genótipos de milho, sendo cinco desenvolvidos pelo SMGP-CECA-UFAL: Alagoano, Branca, Nordestino, São Luiz e Viçosense; duas variedades comerciais; uma desenvolvida pela Empresa Brasileira de Pesquisa Agropecuária (EMBRAPA): BR 106 (Pé de Boi), a outra pela CATI-SP (AL Bandeirante); e uma variedade crioula procedente do médio sertão alagoano (Jabotão). No Grupo 2, foram avaliados dois espaçamentos: $0,6 \mathrm{~m} \times 0,20 \mathrm{~m} \mathrm{e} \mathrm{0,8} \mathrm{m} \times 0,2 \mathrm{~m}$, com 2 plantas por cova, representando as densidades populacionais de 166.667 e 125.000 plantas.ha $^{-1}$, respectivamente.

No Experimento 1 utilizou-se o delineamento experimental em blocos casualizados, no esquema fatorial de $8 \times 2$, com três repetições, totalizando 48 parcelas experimentais. Cada parcela experimental foi constituída de 4 fileiras de $6 \mathrm{~m}$ de comprimento com 2 plantas por cova. Aárea total da parcela foi de $14,40 \mathrm{~m}^{2}$ para o espaçamento de $0,6 \mathrm{~m} \times 0,2 \mathrm{~m}$ e de $19,20 \mathrm{~m}^{2}$ para 0 espaçamento de 0,8 $\mathrm{m} \times 0,2 \mathrm{~m}$. Cada parcela teve duas áreas úteis, uma para a produção de silagem e a outra para a relação espiga, folha e colmo.

Antes da semeadura, foram retiradas amostras de solo da área experimental para análise química do solo no Laboratório Central Analítica Ltda, cujos resultados encontram-se na Tabela 1.

Tabela 1. Análise química do solo da área experimental do SMGP/CECA/UFAL, antes da instalação do experimento, Rio Largo-AL, 2013.

\begin{tabular}{|c|c|c|c|c|c|c|c|c|c|}
\hline $\mathrm{pH}$ & $P$ & $\mathrm{H}+\mathrm{AL}$ & $\mathrm{Al}$ & $\mathrm{Ca}+\mathrm{Mg}$ & $\mathrm{K}$ & $\mathrm{Na}$ & SB & $\mathrm{T}$ & V \\
\hline $\mathrm{H}_{2} \mathrm{O}$ & \multicolumn{9}{|c|}{ 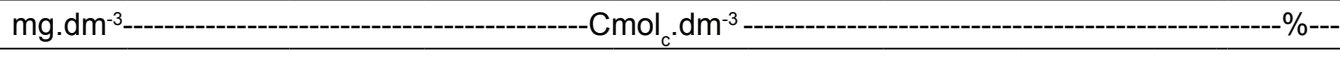 } \\
\hline 5,8 & 56 & 3,1 & 0,02 & 6,5 & 73 & 21 & 6,8 & 9,9 & 68,6 \\
\hline
\end{tabular}

Fonte: Central Analítica, 2013.

O preparo do solo da área experimental foi realizado com uma aração e duas gradagens. Dois dias após essas operações, foi realizada a adubação nitrogenada, com $50 \mathrm{~kg}$.ha-1 de Nitrogênio em fundação, tendo como fonte o fertilizante Uréia, e em seguida, o plantio das sementes dos genótipos de milho nos respectivos espaçamentos, de forma manual, sendo distribuídas cinco sementes por cova espaçadas a 20 $\mathrm{cm}$ ao longo de cada fileira de $6 \mathrm{~m}$ de comprimento. Aos 15 e 25 dias após o plantio realizou-se a adubação em cobertura com 50 kg.ha-1 de Nitrogênio em cada período. Quanto ao uso de corretivos e dos macros elementos Fósforo e Potássio, não houve necessidade de aplicação dos mesmos de acordo com a análise de solo. Porém, com o desenvolvimento da cultura foi observado à deficiência nutricional do macro elemento fósforo em função da alta densidade de plantas avaliadas, a qual foi suprida através da aplicação, via foliar, de fosfato ácido de potássio na dosagem de $5 \%$ em cada aplicação através de pulverizador costal em duas aplicações, aos 30 e 45 dias após o plantio.

Após a emergência das plântulas, procedeuse 0 desbaste ( 15 dias após o plantio) permanecendo dez plantas por metro linear (2 plantas/cova), estabelecendo assim, as densidades populacionais propostas (166.667 e 125.000 plantas.ha $^{-1}$ ).

Durante a condução do experimento foram realizadas entre 2 a 3 irrigações semanais quando necessário para suprir a necessidade da cultura, de acordo com as condições hídricas do solo (capacidade de campo), levando também em consideração as condições meteorológicas do período (Tabela 2).

Tabela 2. Resumo mensal dos dados meteorológicos para Precipitação $(\mathrm{mm})$, Temperatura do $\operatorname{Ar}\left({ }^{\circ} \mathrm{C}\right)$, Umidade

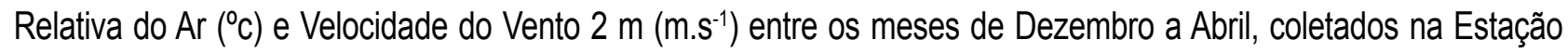
Agrometeorológica localizada no Centro de Ciências Agrárias CECA/UFAL, no Município de Rio Largo-AL, 2013/2014.

\begin{tabular}{lcccccc}
\hline Dados Meteorológicos & Dezembro & Janeiro & Fevereiro & Março & Abril & Total \\
\hline Precipitação $(\mathrm{mm})$ & 12,7 & 53,5 & 68,3 & 44,7 & 188,7 & 367,9 \\
\hline Temp. do $\operatorname{Ar}\left({ }^{\circ} \mathrm{C}\right)$ Min. & 19,4 & 20,3 & 20,8 & 21,5 & 21,3 & \\
\hline Temp. do Ar $\left({ }^{\circ} \mathrm{C}\right)$ Máx. & 33,9 & 32,0 & 31,3 & 32,0 & 34,1 & \\
\hline Temp. do Ar $\left({ }^{\circ} \mathrm{C}\right)$ Média & 25,6 & 25,5 & 25,5 & 25,8 & 25,9 & \\
\hline Um. Rel. do Ar $\left({ }^{\circ} \mathrm{C}\right)$ Min. & 32,4 & 39,6 & 43,2 & 42,5 & 45,3 & \\
\hline Um. Rel. do Ar $\left({ }^{\circ} \mathrm{C}\right)$ Máx. & 91,9 & 91,6 & 92,0 & 92,3 & 92,5 & \\
\hline Um. Rel. do Ar $\left({ }^{\circ} \mathrm{C}\right)$ Média & 74,3 & 73,7 & 76,2 & 76,4 & 79,5 & \\
\hline Veloc. do Vento $2 \mathrm{~m}\left({\left.\mathrm{~m} . \mathrm{s}^{-1}\right)}\right.$ & 1,13 & 2,01 & 1,72 & 1,74 & 1,54 & \\
\hline
\end{tabular}


O controle de plantas daninhas foi realizado através de capinas manual (enxada), com um total de duas operações durante 0 ciclo da cultura (aos 15 e 30 dias após o plantio).

O controle da Spodoptera frugiperda (J. E. Smith, 1797) foi realizado através de cinco aplicações aos 15, 30, 45, 60, 75 dias após o plantio com 0,4 L.ha-1 do inseticida Decis $^{\odot}$ EC 25.u. Na aplicação foi utilizado um pulverizador manual costal com capacidade de $20 \mathrm{~L}$ com pressão de 1 atm e vazão de 0,2 Galões.

As características avaliadas no experimento 1 foram:

Diâmetro de Colmo (mm): medido a $10 \mathrm{~cm}$ do solo com o uso de paquímetro em 6 plantas por parcela aos 95 dias;

Altura de planta $(\mathrm{m})$ : medida com 0 auxílio de uma trena, considerando-se a distância do colo da planta ao ápice do pendão, em 6 plantas por parcela aos 95 dias;

Rendimento de Massa Verde da Planta Inteira $\left(\right.$ t.ha $\left.^{-1}\right)$ : determinado com o auxílio de uma balança de precisão de marca Magna, onde foram pesadas todas as plantas da área útil aos 95 dias;

Rendimento da Matéria Seca da Planta Inteira (t.ha-1): determinado com o auxílio de uma balança de precisão de marca Magna, onde foram pesadas todas as plantas da área útil que foram colhidas aos 95 dias, após a secagem em estufa a $105^{\circ} \mathrm{C}$ por 24 horas;

Contribuição de Espigas na Matéria Verde da Planta Inteira (\%): determinada através da relação entre o rendimento da matéria verde da planta inteira e o rendimento da matéria verde das espigas, expresso em percentagem;

Contribuição de Folhas na Matéria Verde da Planta Inteira (\%): determinada através da relação entre 0 rendimento da matéria verde da planta inteira e o rendimento da matéria verde das folhas, expresso em percentagem;

Contribuição de Colmos na Matéria Verde da Planta Inteira (\%): determinada através da relação entre o rendimento da matéria verde da planta inteira e o rendimento da matéria verde dos colmos, expresso em percentagem.

O Experimento 2 foi realizado a partir de plantas colhidas na área útil do experimento 1 para a produção de silagem, em que utilizou-se 0 delineamento inteiramente casualizado, no esquema fatorial de $8 \times 2$, com três repetições, totalizando 48 parcelas experimentais. Cada parcela experimental foi constituída por um silo experimental, confeccionado por um cano de PVC de 0,50 m de comprimento por $0,10 \mathrm{~m}$ de diâmetro, com volume de 0,157 $\mathrm{m}^{3}$.

A colheita das plantas para a produção de silagem ocorreu aos 95 dias após o plantio, quando os grãos estavam no estádio farináceo. Após a colheita no campo as 20 plantas foram pesadas e trituradas em forrageira de marca Laborentus. Em seguida, 0 material foi inserido e compactado manualmente em silos experimentais, e vedado com lona de polietileno.

Após 60 dias, cada silo foi aberto e retirada uma amostra, a qual foi enviada ao Laboratório de Nutrição Animal do CECA-UFAL para a determinação das características:

Percentual de Matéria Seca da Silagem (\%): determinado em laboratório, a partir de uma amostra retirada após a abertura do silo experimental, em torno de $200 \mathrm{~g}$, a qual foi secada em estufa a $105^{\circ} \mathrm{C}$ por 24 horas;

Rendimento de Matéria Seca da Silagem (t.ha1): determinado a partir do percentual de matéria seca da silagem sobre 0 rendimento de massa verde da planta inteira;

Rendimento de Silagem (t.ha ${ }^{-1}$ ): estimado através da regra de três inversa entre o rendimento de massa verde da planta inteira, o percentual de matéria seca da planta inteira e o percentual de matéria seca da silagem.

As análises de variância foram realizadas seguindo as recomendações de Ferreira (2000), sendo aplicado o teste $\mathrm{F}$ na comparação de médias dos arranjos espaciais e 0 teste de Tukey a $5 \%$ de probabilidade na comparação de médias de genótipos de milho e de genótipos de milho dentro de cada arranjo, utilizando o aplicativo computacional SISVAR (Ferreira, 2003). Os dados de percentual de matéria seca da silagem foram transformados em arco seno. A apresentação das médias dos genótipos e dos arranjos espaciais para a variável percentual de matéria seca da silagem foi com os dados originais e a comparação entre elas foi com os dados transformados.

\section{RESULTADOS E DISCUSSÃO}

De acordo com o teste $F$ para a fonte de variação genótipos, observa-se diferença significativa a $1 \%$ de 
probabilidade apenas para a Altura de Plantas (AP) e a $5 \%$ de probabilidade, para as variáveis Diâmetro do Colmo (DC), Rendimento de Massa Verde da Planta Inteira (RMVPI), Contribuição da Espiga na Massa Verde da Planta Inteira (CEMVPI) e Contribuição de Colmo na Massa Verde da Planta Inteira (CCMVPI). Para os arranjos espaciais, houve diferença significativa a $5 \%$ de probabilidade apenas para o RMVPI e para a Interação Genótipos x Arranjos Espaciais não houve diferença significativa para nenhuma das variáveis. Os coeficientes de variação foram segundo Ferreira (2000) de ótima precisão experimental para AP, DC, CEMVPI e CFMVPI, boa precisão para CCMVPI, regular para RMVPI e aceitável para RMSPI (Tabela 3).

Tabela 3. Resumo das análises de variância e coeficientes de variação para as variáveis avaliadas no desempenho de genótipos de milho em dois arranjos espaciais.

\begin{tabular}{ccccccccc}
\hline \multirow{2}{*}{ Fontes de Variação } & \multirow{2}{*}{ GL } & \multicolumn{7}{c}{ QM } \\
\cline { 3 - 9 } & & AP & DC & RMVPI & RMSPI & CEMVPI & CFMVPI & CCMVPI \\
\hline Genótipo (G) & 7 & $0,218^{\text {** }}$ & $6,09^{*}$ & $260,34^{*}$ & $41,15^{\text {ns }}$ & $1,33^{*}$ & $0,07^{\text {ns }}$ & $1,59^{*}$ \\
Arranjo Espacial (AE) & 1 & $0,012^{\text {ns }}$ & $6,19^{\text {ns }}$ & $555,96^{*}$ & $32,88^{\text {ns }}$ & $0,79^{\text {ns }}$ & $0,02^{\text {ns }}$ & $1,28^{\text {ns }}$ \\
Interação G x AE & 7 & $0,019^{\text {ns }}$ & $2,28^{\text {ns }}$ & $92,22^{\text {ns }}$ & $19,25^{\text {ns }}$ & $0,07^{\text {ns }}$ & $0,03^{\text {ns }}$ & $0,15^{\text {ns }}$ \\
Blocos & 2 & 0,062 & 8,28 & 1724,16 & 100,71 & 0,52 & 0,26 & 1,48 \\
Resíduo & 30 & 0,029 & 2,29 & 106,03 & 25,92 & 0,41 & 0,12 & 0,53 \\
\hline CV (\%) & & 6,46 & 7,71 & 16,66 & 25,88 & 9,39 & 8,45 & 12,57 \\
\hline
\end{tabular}

ns: Não significativo a $5 \%$ de probabilidade pelo teste $F$. ${ }^{* *}$ : Significativo a $1 \%$ de probabilidade pelo teste $F$. *: Significativo a $5 \%$ de probabilidade pelo teste F. Nota: AP: Altura de Planta, DC: Diâmetro do Colmo, RMVPI: Rendimento de Matéria Verde da Planta Inteira, RMSPI: Rendimento de Matéria Seca da Planta Inteira, CEMVPI: Contribuição de Espigas na Matéria Verde da Planta Inteira, CFMVPI: Contribuição de Folhas na Matéria Verde da Planta Inteira, CCMVPI: Contribuição de Colmos na Matéria Verde da Planta Inteira.

Para a AP, os genótipos Branca (2,82 m), São Luiz (2,81 m), Jabotão (2,77 m) e Alagoano (2,73 m) não diferiram entre si e apresentaram as maiores altura de planta. As variedades comerciais AL Bandeirante $(2,37 \mathrm{~m})$ eBR 106 (2,33 m) obtiveram as menores alturas de plantas e não diferiram entre si. Já os genótipos Viçosense (2,65 $\mathrm{m})$ e Nordestino $(2,60 \mathrm{~m})$ não diferiram dos genótipos com maiores e menores alturas de planta, apresentando desempenhos intermediários (Tabela 4). Verifica-se que os genótipos Alagoano, Branca, Nordestino, São Luis, Viçosense e Jabotão tiveram em média, 38 centímetros a mais que as variedades comerciais utilizadas como testemunhas, o que favorece um maior acúmulo de massa verde, sendo vantajoso quando se trata de material utilizado para silagem, implicando assim, em maior volume de matéria verde como volumoso.

Tabela 4. Médias dos genótipos para a produção de silagem.

\begin{tabular}{|c|c|c|c|c|c|c|c|}
\hline GENÓTIPOS & $\begin{array}{l}\text { AP } \\
(\mathrm{m})\end{array}$ & $\begin{array}{c}\text { DC } \\
(\mathrm{mm})\end{array}$ & $\begin{array}{l}\text { RMVPI } \\
\left(\text { t.ha }^{-1}\right)\end{array}$ & $\begin{array}{l}\text { RMSPI } \\
\left(\text { t.ha-1) }^{-1}\right)\end{array}$ & $\begin{array}{c}\text { CEMVP } \\
(\%)\end{array}$ & CFMVPI (\%) & $\begin{array}{c}\text { CCMVPI } \\
(\%)\end{array}$ \\
\hline ALAGOANO & $2,73 \mathrm{~b}$ & $20,08 a b$ & $61,87 a b$ & 19,43 a & $47,52 a b$ & 17,89 a & $34,60 a b$ \\
\hline BRANCA & $2,82 \mathrm{~b}$ & $21,18 b$ & $71,17 \mathrm{~b}$ & $23,53 a$ & $50,82 a b$ & $16,51 \mathrm{a}$ & $32,67 a b$ \\
\hline NORDESTINO & $2,60 a b$ & $19,43 a b$ & $61,05 a b$ & 17,05 a & $49,10 a b$ & $18,65 \mathrm{a}$ & $32,26 a b$ \\
\hline SÃO LUIZ & $2,81 \mathrm{~b}$ & $20,42 a b$ & $58,56 a b$ & 17,86 a & $47,18 a b$ & $17,46 a$ & $35,36 a b$ \\
\hline VIÇOSENSE & $2,65 a b$ & $20,32 a b$ & $62,02 \mathrm{ab}$ & $22,03 \mathrm{a}$ & $45,38 a b$ & $17,31 \mathrm{a}$ & $37,31 \mathrm{ab}$ \\
\hline JABOTÃO & $2,77 \mathrm{~b}$ & $18,53 a b$ & $70,01 \mathrm{~b}$ & $22,24 \mathrm{a}$ & $35,37 \mathrm{a}$ & $17,02 \mathrm{a}$ & $47,61 \mathrm{~b}$ \\
\hline BR 106 & $2,33 \mathrm{a}$ & $18,31 \mathrm{a}$ & $50,36 a$ & $16,58 \mathrm{a}$ & 56,89 b & $16,17 \mathrm{a}$ & $26,94 \mathrm{a}$ \\
\hline AL BANDEIRANTE & $2,37 \mathrm{a}$ & $18,99 a b$ & $59,24 a b$ & 18,60 a & $51,74 \mathrm{~b}$ & $18,77 \mathrm{a}$ & 29,49 a \\
\hline MÉDIA GERAL & - & - & - & 19,67 & - & 17,47 & - \\
\hline$\Delta_{5 \%}$ & 0,32 & 2,85 & 19,34 & 9,56 & 16,01 & 5,56 & 15,96 \\
\hline
\end{tabular}

Médias seguidas pela mesma letra na coluna não diferem estatisticamente entre si pelo teste de Tukey a $5 \%$ de probabilidade. AP: Altura de Planta, DC: Diâmetro do Colmo, RMVPI: Rendimento de Matéria Verde da Planta Inteira, RMSPI: Rendimento de Matéria Seca da Planta Inteira, CEMVPI: Contribuição de Espigas na Matéria Verde da Planta Inteira, CFMVPI: Contribuição de Folhas na Matéria Verde da Planta Inteira, CCMVPI: Contribuição de Colmos na Matéria Verde da Planta Inteira. 
Segundo Von Pinho et al. (2007), materiais com porte maior são de extrema importância para a produção de forragem visando a produção de silagem. PAZIANI et al. (2009) observaram que plantas de altura superior apresentam alta correlação com a produção de matéria verde, matéria seca e produção de grãos.

Com relação à variável $\mathrm{DC}$, o genótipo Branca obteve o maior diâmetro, com 21,18 mm, diferindo apenas da variedade da Embrapa BR 106 que apresentou o menor diâmetro do colmo, com 18,31 $\mathrm{mm}$, enquanto que os demais genótipos não diferiram dos genótipos Branca e BR 106.

Observa-se que os genótipos Viçosense, Alagoano, Branca, Nordestino e São Luis tiveram maiores diâmetros de colmo, em média, 1,68 milímetros a mais que a variedade crioula Jabotão e as variedades comerciais BR 106 e AL Bandeirante. Segundo Sangoi et al. (2001) e Stacciarini et al. (2010), a diminuição do espaçamento entre linhas reduz o diâmetro do colmo por conta da competição por luz, provocando maior crescimento em altura em detrimento ao crescimento radial do colmo. Fato esse que não foi observado no presente trabalho, onde plantas altas tiveram maiores diâmetros de colmo, resultados semelhantes foram encontrados pelos autores Paixão et al. (2008), Pereira et al. (2010), Silva (2012), Costa (2013) e Falcão (2014) utilizando os mesmos genótipos.

De acordo com Fancelli e Dourado Neto (2000), quanto maior o diâmetro de colmos mais sólidos solúveis será armazenado, sendo utilizados na formação de grãos e, consequentemente, resultando em maior produtividade e qualidade da silagem obtida.

Não houve diferença significativa entre os genótipos de milho para as variáveis RMSPI e CFMVPI onde obtiveram médias gerais de 19,67 t.ha-1e $17,47 \%$, respectivamente.

Quanto à variável RMVPI, o genótipo Branca e a variedade crioula Jabotão apresentaram os maiores rendimentos de matéria verde da planta inteira e diferiram estatisticamente da variedade comercial BR 106, enquanto que os demais genótipos tiveram um comportamento intermediário entre estes.

Com relação à variável CEMVPI, as variedades comerciais BR 106 e AL Bandeirante apresentaram as maiores contribuições de espigas no rendimento de matéria verde da planta inteira e diferiram estatisticamente da variedade crioula Jabotão, enquanto que os demais genótipos tiveram um comportamento intermediário entre estes.

Para a variável CCMVPI, a variedade crioula Jabotão apresentou a maior contribuição de colmos no rendimento de matéria verde da planta inteira e diferiu estatisticamente das variedades comerciais BR $106 \mathrm{e}$ AL Bandeirante, enquanto que os demais genótipos tiveram um comportamento intermediário entre estes.

Observa-se que os genótipos de milho avaliados no presente trabalho tiveram um rendimento de matéria verde da planta inteira variando de 50,36 a 71,17 t.ha ${ }^{-1}$, respectivamente, para BR 106 e Branca. Tais resultados demonstram o excelente desempenho dos genótipos avaliados, onde os genótipos BR 106, AL Bandeirante e São Luiz tiveram um rendimento acima de 50 t.ha $^{-1}$, Nordestino, Alagoano e Viçosense acima de 60 t.ha $^{-1}$, e Branca e Jabotão acima de 70 t.ha $^{-1}$, quando comparados com os resultados obtidos por diversos autores (Ferrari Júnior et al., 2005; Neumann et al., 2002; Mello et al., 2005; Nakachi et al., 2007; Guareschi et al., 2010; Cancellier et al., 2011).

No entanto, para o uso de silagem, é necessário observar a contribuição dos componentes estruturais da planta de cada genótipo (espigas, folhas e colmos), pois nem sempre o genótipo que tenha o maior rendimento de matéria verde da planta inteira pode ser indicado para essa finalidade, visto que a qualidade da silagem depende do maior percentual de espigas e do menor percentual de colmos.

Avaliando-se os componentes estruturais da planta nos genótipos estudados no presente trabalho, verifica-se que a variedade crioula Jabotão, apesar de ter um alto rendimento de matéria verde da planta inteira $\left(70,01\right.$ t.ha $\left.^{-1}\right)$, é a menos recomendada para silagem, pois apresentou o menor percentual de espigas $(35,37 \%)$ e o maior percentual de colmos $(47,61 \%)$, enquanto que as variedades comerciais $B R$ 106 e AL Bandeirante tiveram os maiores percentuais de espigas (em média, 54,32\%) e os menores percentuais de colmos (em média, 28,22\%), mas tiveram os menores rendimentos de matéria verde da planta inteira (em média, 54,81 t.ha-1). Já os genótipos Viçosense, Alagoano, São Luis, Nordestino e Branca tiveram um comportamento intermediário em relação a estes, com percentual médio de espigas de $48,00 \%$ e percentual médio de colmos de $34,44 \%$, sendo estes genótipos os mais indicados para produção de silagem, 
especialmente o genótipo Branca com um rendimento de matéria verde da planta inteira de 71,17 tha-1 e com os percentuais de espigas e de colmos de 50,82 e $32,67 \%$, respectivamente.

$\mathrm{Na}$ Tabela 5 encontram-se as médias das seguintes variáveis Rendimento de Massa Verde da Planta Inteira (RMVPI), Rendimento de Matéria Seca da Planta Inteira (RMSPI), Contribuição de Espigas na Matéria Verde da Planta Inteira (CEMVPI), Contribuição de Folhas na Matéria Verde da Planta
Inteira (CFMVPI) e Contribuição de Colmos na Matéria Verde da Planta Inteira (CCMVPI) nos dois arranjos espaciais, onde resultaram em duas densidades populacionais, em que de acordo com o teste $\mathrm{F}$ podese concluir que não houve diferença significativa entre os arranjos espaciais para as variáveis AP, DC RMSPI, CEMVPI, CFMVPI, CCMVPI e RV ao nível de $5 \%$ de probabilidade, tendo as seguintes médias: $2,63 \mathrm{~cm}$,

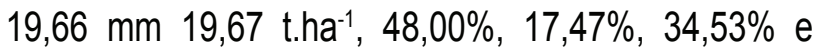
50,25 t.ha $^{-1}$, respectivamente.

Tabela 5. Médias das variáveis avaliadas em dois espaçamentos entre linhas.

\begin{tabular}{cccccccc}
\hline Arranjo Espacial & $\begin{array}{c}\text { AP } \\
(\mathrm{m})\end{array}$ & $\begin{array}{c}\text { DC } \\
(\mathrm{mm})\end{array}$ & $\begin{array}{c}\text { RMVPI } \\
\left(\mathrm{t}^{2} \mathrm{a}^{-1}\right)\end{array}$ & $\begin{array}{c}\text { RMSPI } \\
\left(\text { t.ha }{ }^{-1}\right)\end{array}$ & $\begin{array}{c}\text { CEMVPI } \\
(\%)\end{array}$ & $\begin{array}{c}\text { CFMVPI } \\
(\%)\end{array}$ & $\begin{array}{c}\text { CCMVPI } \\
(\%)\end{array}$ \\
\hline$(0,8 \times 0,2 \mathrm{~m})$ & $2,65 \mathrm{a}$ & $20,02 \mathrm{a}$ & $58,38 \mathrm{a}$ & $18,84 \mathrm{a}$ & $46,30 \mathrm{a}$ & $17,28 \mathrm{a}$ & $36,42 \mathrm{a}$ \\
$(0,6 \times 0,2 \mathrm{~m})$ & $2,62 \mathrm{a}$ & $19,30 \mathrm{a}$ & $65,19 \mathrm{~b}$ & $20,49 \mathrm{a}$ & $49,70 \mathrm{a}$ & $17,66 \mathrm{a}$ & $32,64 \mathrm{a}$ \\
\hline MÉDIA GERAL & 2,63 & 19,66 & - & 19,67 & 48,00 & 17,47 & 34,53 \\
\hline
\end{tabular}

Médias seguidas pela mesma letra na coluna não diferem estatisticamente entre si pelo teste de Tukey a $5 \%$ de probabilidade. AP: Altura de Planta, DC: Diâmetro do Colmo, RMVPI: Rendimento de Matéria Verde da Planta Inteira, RMSPI: Rendimento de Matéria Seca da Planta Inteira, CEMVPI: Contribuição de Espigas na Matéria Verde da Planta Inteira, CFMVPI: Contribuição de Folhas na Matéria Verde da Planta Inteira, CCMVPI: Contribuição de Colmos na Matéria Verde da Planta Inteira.

Para a variável RMVPI, houve diferença significativa a $5 \%$ de probabilidade, sendo que 0 arranjo espacial de 0,6 $\times 0,2 \mathrm{~m}$ proporcionou um aumento de $11,66 \%$ no rendimento de matéria verde da planta inteira em comparação com o arranjo 0,8 x 0,2 m.

De acordo com o teste $F$ para a fonte de variação genótipos (Tabela 6), observa-se diferença significativa a $5 \%$ de probabilidade apenas para a variável RSIL, enquanto que as demais foram não significativas ao nível de $5 \%$ de probabilidade. Com relação às fontes de variação arranjo espacial e interação genótipos e arranjo espacial, o teste $F$ não encontrou diferença significativa a $5 \%$ de probabilidade para todas as variáveis estudadas.

Tabela 6. Resumo das análises de variância e coeficientes de variação para as variáveis avaliadas no desempenho de genótipos de milho em dois arranjos espaciais para produção de silagem. (Experimento 2). Rio Largo-AL, 2014.

\begin{tabular}{ccccc}
\hline Fontes de Variação & \multicolumn{4}{c}{ QM } \\
\cline { 2 - 5 } & GL & RSIL & \%MSSIL & RMSSIL \\
\hline Genótipos (G) & 7 & $523342964,70^{*}$ & $0,585406^{\mathrm{ns}}$ & $34222827,966^{\mathrm{ns}}$ \\
Arranjos Espaciais (AE) & 1 & $312933673,61^{\mathrm{ns}}$ & $0,000111^{\mathrm{ns}}$ & $76286293,38^{\mathrm{ns}}$ \\
Interação G x AE $_{\text {Blocos }}$ & 7 & $88395411,86^{\mathrm{ns}}$ & $0,230724^{\mathrm{ns}}$ & $15965291,566^{\mathrm{ns}}$ \\
Resíduo & 2 & & & - \\
CV (\%) & 30 & 212137476,21 & 0,326221 & 23593728,25 \\
\hline
\end{tabular}

ns: Não significativo a $5 \%$ de probabilidade pelo teste $\mathrm{F}$. ${ }^{*}$ : Significativo a $1 \%$ de probabilidade pelo teste $\mathrm{F} .{ }^{*}$ : Significativo a 5\% de probabilidade pelo teste F.Nota: RSIL: Rendimento de Silagem, \%MSSIL: Percentual de Matéria Seca da Silagem e RMSSIL: Rendimento de Matéria Seca da Silagem.

Os coeficientes de variação das variáveis avaliadas apresentaram valores entre $9,08 \%$ a $29,62 \%$ para, respectivamente, \%MSSIL e RSIL. Determinadas variáveis, como as relacionadas com rendimento, sofrem muita influência do ambiente. Em função disso, os seus coeficientes de variação são, geralmente, mais altos. No entanto, verificou-se nesse trabalho que a variável \%MSSIL foi a única que teve uma ótima precisão experimental, segundo Ferreira (2000).

Quanto à variável RSIL, a variedade crioula Jabotão apresentou o maior rendimento, com 64,55 
t.ha ${ }^{-1}$ diferindo apenas da variedade comercial BR 106 que obteve o menor rendimento, com 35,35 t.ha- ${ }^{-1}$. A variedade comercial AL Bandeirante e os demais genótipos apresentaram um desempenho intermediário entre estas, com um rendimento médio de 47,66 t.ha-1 e 49,16 t.ha-1, respectivamente.

Com relação às variáveis MSSIL e RMSSIL, não houve diferença significativa os genótipos de milho, com médias gerais de 39,91\% e 21,82 t.ha-1 ${ }^{-1}$, respectivamente.

O conhecimento do percentual de matéria seca contido na silagem é importante, pois é com base nele que se estabelece o cálculo da dieta, já que o consumo do alimento pelos animais é estabelecido em $\mathrm{kg}$ de MS/animal/dia, onde quanto menor o teor de matéria seca, maior será o consumo. Existe uma faixa de percentagem de matéria seca que é ideal tanto para o consumo como para a produção e conservação da silagem, que, no caso do milho, fica entre 28 e $35 \%$ MS. Por outro lado, teores de MS inferiores a $25 \%$ propiciam ambiente favorável à proliferação e ao desenvolvimento de bactérias produtoras de ácido butírico e também a perdas de princípios nutritivos, por lixiviação, e intensa degradação de proteínas (Deminicis, 2009).

Todos os genótipos de milho avaliados no presente trabalho, com exceção da variedade crioula Jabotão, apresentaram teores de MS da silagem superiores à faixa ideal para conservação da silagem, indicando que tais genótipos têm um grande potencial para uso na alimentação animal.

De acordo com o teste $F$, não houve diferença significativa entre os arranjos espaciais para todas as variáveis ao nível de $5 \%$ de probabilidade, tendo as seguintes médias: 49,17 tha-1 ${ }^{-1}, 39,91 \%$ e 21,82 t.ha-1, respectivamente, para RSIL, \%MSSIL e RMSSIL.

Desta forma, conclui-se que o aumento da densidade populacional através do arranjo espacial proporciona maior matéria verde da planta inteira, sem alterar as demais características agronômicas;

As variedades de milho Alagoano, Branca, Nordestino, São Luiz, Viçosense, BR 106 e AL Bandeirante apresentaram características favoráveis à produção de silagem.

Na produção de milho para silagem de alta qualidade, a variedade Branca é a mais indicada por ter um alto rendimento de matéria verde da planta inteira, em torno de 71 toneladas de forragem por hectare, uma alta contribuição de espigas, acima de $50 \%$, e uma baixa contribuição de colmos, em torno $33 \%$.

Tabela 7. Médias das 03 variáveis avaliadas em oito genótipos de milho. (Experimento 2).

\begin{tabular}{cccc}
\hline GENÓTIPOS & $\begin{array}{c}\text { RSIL } \\
\left(\mathrm{t} . \mathrm{ha}^{-1}\right)\end{array}$ & $\begin{array}{c}\% \text { MSSIL } \\
(\%)\end{array}$ & $\begin{array}{c}\text { RMSSIL } \\
\left(\text { t.ha } \mathrm{a}^{-1}\right)\end{array}$ \\
\hline ALAGOANO & $44,54 \mathrm{ab}$ & $42,26 \mathrm{a}$ & $23,05 \mathrm{a}$ \\
BRANCA & $55,84 \mathrm{ab}$ & $42,58 \mathrm{a}$ & $26,96 \mathrm{a}$ \\
NORDESTINO & $43.77 \mathrm{ab}$ & $39,11 \mathrm{a}$ & $21,91 \mathrm{a}$ \\
SÃO LUIZ & $44,50 \mathrm{ab}$ & $39,63 \mathrm{a}$ & $20,33 \mathrm{a}$ \\
VIÇOSENSE & $57,16 \mathrm{ab}$ & $37,04 \mathrm{a}$ & $20,50 \mathrm{a}$ \\
JABOTÃO & $64,55 \mathrm{~b}$ & $34,11 \mathrm{a}$ & $21,49 \mathrm{a}$ \\
BR 106 & $35,35 \mathrm{a}$ & $46,90 \mathrm{a}$ & $21,25 \mathrm{a}$ \\
AL BANDEIRANTE & $47,66 \mathrm{ab}$ & $37,69 \mathrm{a}$ & $19,07 \mathrm{a}$ \\
\hline MÉDIA GERAL & - & 39,91 & 21,82 \\
\hline$\Delta_{5 \%}$ & 27,25 & 12,99 & 9,13 \\
\hline
\end{tabular}

1/: Médias seguidas pela mesma letra, em cada coluna, não diferem entre si pelo teste de Tukey a $5 \%$ de probabilidade. Nota: RSIL: Rendimento de Silagem, \%MSSIL: Percentual de Matéria Seca da Silagem e RMSSIL: Rendimento de Matéria Seca da Silagem.

Tabela 8. Médias das variáveis avaliadas em dois arranjos espaciais. (Experimento 2).

\begin{tabular}{|c|c|c|c|}
\hline Arranjo Espacial & $\begin{array}{c}\text { RSIL } \\
(\text { t.ha-1) }\end{array}$ & $\begin{array}{c}\begin{array}{c}\text { \%MSSIL } \\
(\%)\end{array} \\
\end{array}$ & $\begin{array}{l}\text { RMSSIL } \\
\text { (t.ha-1) }\end{array}$ \\
\hline$(0,8 \times 0,2 \mathrm{~m})$ & $46,62 \mathrm{a}$ & $39,89 a$ & $20,56 \mathrm{a}$ \\
\hline$(0,6 \times 0,2 \mathrm{~m})$ & 51,73 a & $39.94 \mathrm{a}$ & $23,08 \mathrm{a}$ \\
\hline MÉDIA GERAL & 49,17 & 39,91 & 21,82 \\
\hline
\end{tabular}

1/: Médias seguidas pela mesma letra, em cada coluna, não diferem entre si pelo teste de $\mathrm{F}$ a $5 \%$ de probabilidade. Nota RSIL: Rendimento de Silagem, \%MSSIL: Percentual de Matéria Seca da Silagem e RMSSIL: Rendimento de Matéria Seca da Silagem. 


\section{REFERÊNCIAS BIBLIOGRÁFICAS}

Alvarez, C.G.D.; Pinho, R.G.; Borges, I.D. Avaliação de características agronômicas e de produção de forragens e grãos de milho em diferentes densidades de semeadura e espaçamentos entre linhas. Ciência $e$ Agrotecnologia, 2006, 30, 402-408.

Brachtvogel, E.L.; Pereira, F.R.S.; Cruz, S.C.S.; Abreu, M.L.; Bicudo, S.J. População, arranjo de plantas uniformes e a competição intraespecifica em milho. Revista Tropica, 2012, 6, 1, 75-83.

Cancellier, L.L; Afférri, F.S; Dutra, D.P; Leão, F.F; Peluzio, J.M; Carvalho, E.V. Potencial forrageiro de populações de milho no sul do Estado de Tocantins. Bioscience Journal, 2011, 27, 1, 77-87.

Cardoso, M.J.; Ribeiro, V.Q. Produtividade de grãos de milho sob espaçamento reduzido em áreas de cerrado do Meio-Norte brasileiro. 2013. Disponível em: http://ainfo. cnptia.embrapa.br/digital//bitstream/item/94120/1/201383-8452.pdf, Acesso as 19:24 h, do dia 29/07/2015.

CONAB (Companhia Nacional de Abastecimento). V.2-Safra 2014/2015, N.5-Quinto Levantamento. Fevereiro/2015.

Costa, C.; Creste, C.R.; Arrigoni, M.B.; Silveira, A.C.; Rosa, G.J.M.; Bicudo, S.J. Potencial para ensilagem, composição química e qualidade da silagem de milho com diferentes proporções de espigas. Acta Scientiarum, 2000, 22, 3, 835-841.

Costa, K.D.Avaliação De Genótipos de Milho Em Diferentes Densidades Populacionais. Dissertação de mestrado em agronomia (Produção Vegetal), 52 p., Ufal, 2013.

Cuenca, M.A.G.; Názario, C.C.; Mandarino, D.C. Características e Evolução da cultura do milho no estado de alagoas entre 1990 e 2003. Embrapa, 2005.

Demétrio, C.S.; Fornasieri Filho, D.; Cazetta, J.O.; Cazetta, D.A. Desempenho de híbridos de milho submetidos a diferentes espaçamentos e densidades populacionais. Pesquisa Agropecuária Brasileira, 2008, 43, 12, 1691 - 1697.

Deminicis, B.B.; Vieira, H.D.; Jardim, J.G.; Araújo, S.A.C.; Chambela Neto, A.; Oliveira, V.C.; Lima, E.S. Silagem de milho - Características agronômicas e considerações. Revista electrónica de veterinária, 2009, 10, 2, 1- 18.
Duarte, J.O.; Cruz, J.C.; Garcia, J.C.; Mattoso, M.J. Economia da Produção. In: CRUZ, J. C. (Ed.). Cultivo do milho. Sete Lagoas: Embrapa Milho e Sorgo, 2009. (Embrapa Milho e Sorgo. Sistema de Produção, 1) Disponível em: <http://www.cnpms.embrapa.br/ publicacoes/milho_6_ed/economia.htm>. Acesso em: 28 jul. 2014.

Falcão, R.F. Avaliação de populações alagoanas e variedades comerciais e crioulas de milho (Zea mays L.) em dois municípios do sertão alagoano. Dissertação de mestrado em Agronomia (Produção Vegetal), 53 p., UFAL, 2014.

Fancelli, A.L.; Dourado Neto, D. Produção de milho. Guaíba: Agropecuária, 2000.

Farnham, D.E.; Myli, J.; Haden, D. Row width effects on corn yield at varying plant densities.Disponível em: <http: // www.reimangardens.org/farms/2000reports/ monay/ RowWidthEffectsonCornY.pdf.>Acesso em: 14 nov. 2014.

Ferrari Junior, E.; Possenti, R.A.; Lima, M.L.P.; Nogueira, J.R.; Andrade, J.B. Características agronômicas, composição química e qualidade de silagens de oito cultivares de milho. B. Indústria Animal, N. Odessa, 2005, 62, 1, $19-27$.

Ferreira, D.F. Programa SISVAR: sistema de análise de variância, Versão 4,6 (Build 6,0), Lavras, DEX/UFLA, 2003.

Ferreira, P.V. Estatística experimental aplicada à agronomia. 3. ed. Maceió: EDUFAL, 2000.

Guareschi, R.F; Brasil, R.B; Perin, A; R, J. M. M. Produção de silagem de híbridos de milho e sorgo sem nitrogênio de cobertura em safra de verão. Pesquisa Agropecuária Tropical, 2010, 40, 4, 541-546.

Mello, R.; Nornberg, J.L.; Rocha, M.G.; David, D.B. Características produtivas e Qualitativas de Híbridos de Milho para Produção de Silagem. Revista Brasileira de Milho e Sorgo, 2005, 4, 1, 79-94.

Modolo, A.J.; Carnieletton, R.; Kolling E.M.; Trogello, E.; Sgarbossa, M. Desempenho de híbridos de milho na Região Sudoeste do Paraná sob diferentes espaçamentos entre linhas. Revista Ciência Agronômica, 2010, 41, 3, 435 - 441. 
Nakachi, M.S.; Mello, S.P. Avaliação Quantitativa e Qualitativa da Silagem de Híbridos de Milho (Zea maysL.) sem espigas. Nucleus, 2007, 4. 1-2.

Neumann, M.; Restle, J.; Brondani, I.L. Avaliação de silagem de sorgo (Sorghum bicolor, L. MOENCH) ou milho (Zea mays, L.) na produção de novilhos superprecoce. Revista Brasileira de Milho e Sorgo, 2004, 3, 3, $438-452$.

Neumann, M.; Restle, J.; Mello, R. Características produtivas da planta de diferentes híbridos de milho (ZeamaysL.) para produção de silagem. In: CONGRESSO NACIONAL DE MILHO E SORGO, 24. 2002, Florianópolis. Anais... Florianópolis: ABMS; Embrapa Milho e Sorgo; EPAGRI, 2002. CD-ROM.

Paixão, S.L.; Ferreira, P.V.; Madalena, J.A.S.; Pereira, R.G. Divergência genética e avaliação de populações de milho em diferentes ambientes no Estado de Alagoas. Caatinga, 2008, 21, 4, 191-195.

Paziani, S.F.; Duarte , A.P.; Nussio, L.G.; Gallo, P.B.; Bittar, C.M.M.; Zopollatto, M.; Reco, P.C. Características agronômicas e bromatológicas de híbridos de milho para a produção de silagem. Revista Brasileira de Zootecnia, 2009, 38, 3, 111-117.
Pereira, R.G; Albuquerque, A.W; Nunes, G.H.S; Souza, R.O; Silva, A.D. Comportamento de cultivares de milho nos tabuleiros costeiros do Estado de Alagoas. Revista Verde, 2010, 5, 2, 54-63.

Santos, H.G.; Jacomine, P.K.T.; Anjos, L.H.C.; Oliveira, V.A.; Oliveira, J.B.; Coelho, M.R.; Lumbrebas, J.F.; Cunha, T.J.F. (eds.). Sistema brasileiro de classificação de solos. 2ed. Rio de Janeiro: Embrapa Solos. 2006. 306p.

Silva, J.P. Desempenho de genótipos alagoanos de milho (Zea mays L.) em diferentes densidades de semeadura. Dissertação de mestrado em Agronomia (Produção Vegetal) - UFAL, 53 p. 2012.

Strieder, M.L.; Silva, P.R.F.; Rambo, L.; Bergamaschi, H.; Dalmago, G.A.; Endrigo, P.C.; Jandrey, D.B. Características de dossel e rendimento de milho em diferentes espaçamentos e sistemas de manejo. Pesquisa Agropecuária Brasileira, 2008, 43, 3, 309317.

Von Pinho, R.G; Vasconcelos, R. C; Borges, I.D; Resende, A.V. Produtividade e qualidade da silagem de milho e sorgo em função da época de semeadura. Bragantia, 2007, 66, 2, 235-245. 


\title{
CRESCIMENTO E ACÚMULO DE ÁCIDOS ORGÂNICOS NA SEIVA MINERAL, RAÍZES E EXSUDATOS RADICULARES DE PORTAENXERTOS DE PRUNUS EM FUNÇÃO DA FERTILIZAÇÃO NITROGENADA
}

\author{
Letícia Vanni Ferreira $^{1^{*}}$; Luis Eduardo Corrêa Antunes² \\ ${ }^{1}$ Pós-doutoranda Capes-Embrapa \\ ${ }^{2}$ Pesquisador Embrapa Clima Temperado \\ Autor para correspondência: Letícia Vanni Ferreira. letivf@hotmail.com
}

\begin{abstract}
RESUMO: 0 experimento foi conduzido no período de maio a junho de 2015, em casa de vegetação pertencente ao Vivai Battistini, em Cesena, Itália, onde foram utilizados dois genótipos de porta enxerto de Prunus 'G× N15' e 'GF 677' e duas doses de N: 0 e 8 mM. Objetivou-se caracterizar os ácidos orgânicos presentes em raiz, seiva e exsudatos radiculares de porta enxertos Prunus como mecanismo de resposta à fertilização nitrogenada. Os ácidos orgânicos presentes na seiva e na raiz de 'GF 677' e 'Gx N15' são oxálico, tartárico, málico, ascórbico, cítrico, succínico e fumárico, não ocorrendo diferença significativa entre os genótipos. E os presentes nos exsudatos radiculares dos portaenxertos avaliados foram oxálico, tartárico, málico e fumárico, sendo encontrados em maiores concentrações no genótipo 'GF 677'. A dose de 8 mM de $\mathrm{N}$ não tem efeito nos ácidos orgânicos presentes na seiva e na raiz, porém influencia positivamente na concentração de ácidos orgânicos presentes nos exsudatos radiculares dos portaenxertos 'GF 677' e 'Gx N15', isto é quanto mais N, mais ácidos orgânicos são exsudados.
\end{abstract}

PALAVRAS-CHAVE: exsudação, raiz, xilema.

\section{PLANT GROWTH AND ORGANIC ACIDS IN ROOT SAP, ROOTS AND ROOT EXUDATES OF PRUNUS ROOTSTOCKS IN THE FUNCTION OF NITROGEN FERTILIZATION}

ABSTRACT: The experiment was conducted from May to June 2015, in a greenhouse belonging to Vivai Battistini, in Cesena, Italy. Two Prunus ' $\mathrm{G} \times \mathrm{N} 15$ ' and 'GF 677' rootstock genotypes and two N: 0 and $8 \mathrm{mM}$ doses were used. The objective of this study was to characterize the organic acids present in root, sap and root exudates of Prunus rootstock as a mechanism of response to nitrogen fertilization. The organic acids present in the sap and root of 'GF 677' and 'Gx N15' are oxalic, tartaric, malic, ascorbic, citric, succinic and fumaric, and there is no significant difference between the genotypes. The presence of oxalic, tartaric, malic, and fumaric acids in the root exudates of the evaluated portagrafts were found in greater quantities in the 'GF 677' genotype. The dose of $8 \mathrm{mM} \mathrm{N}$ has no effect on the organic acids present in the sap and root, but it positively influences the concentration of organic acids present in the root exudates of the grafts 'GF 677' and 'Gx N15', that is, the more N, More organic acids are exuded.

KEY WORDS: exudation, root, sap.

\section{INTRODUÇÃO}

Os exsudatos radiculares são substâncias produzidas pelas plantas e liberadas na rizosfera (Monteiro et al., 2012). Sua composição é dependente do estado fisiológico e da espécie da planta, bem como dos microrganismos presentes no solo (Kang et al., 2010). Compostos como carboidratos, aminoácidos, ácidos orgânicos, fenóis, ácidos graxos, vitaminas e enzimas compreendem os principais exsudatos secretados pelas raízes das plantas (Carvalhalis et al., 2011).

Os exsudatos podem reduzir os efeitos de toxidez de alumínio $\left(\mathrm{Al}^{3+}{ }^{3+}\right.$ e de outros metais pesados (Kidd et al., 2001), além de servirem como sinalizadores para 0 estabelecimento de simbioses com rizóbios e fungos micorrízicos (Badri e Vivanco, 2009). As substâncias liberadas pelas raízes podem ainda estimular relações benéficas às plantas, alterar as propriedades do solo, repelir organismos deletérios e inibir o crescimento de espécies competidoras (Mathesius e Watt, 2011).

0 aumento da exsudação radicular ocorre principalmente em situações de estresse nutritivo para as plantas, alterando a química do solo em torno das raízes (Marshner, 1995). Comprovada a influência da 
espécie vegetal na colonização da região rizosférica e tendo em mente que os exsudatos liberados podem exercer grande influência sobre essa característica, seria importante descobrir qual a composição dos exsudatos de Prunus, e se a mesma sofre influência quando recebe um elemento químico na forma de fertilizante, em pelo menos algumas substâncias. Então, em virtude da escassez de informações sobre os efeitos do nitrogênio $(N)$, elemento de maior importância para o gênero Prunus, na exsudação radicular, objetivouse no presente trabalho avaliar o efeito da fertilização nitrogenada nos ácidos orgánicos exsudados pelos porta enxertos Prunus 'G× N15' e 'GF 677'.

\section{MATERIAL E MÉTODOS}

0 experimento foi realizado no período de 15 de maio a 18 de junho de 2015, conducido em casa de vegetação pertencente ao Viveiro de mudas Battistini, no município de Cesena/FC, Itália, com mudas de dois genótipos de porta enxerto Prunus 'G× N15' (Prunus amygdalus $x$ Prunus persica) e 'GF 677' (híbrido de $P$. persica $\times P$. amygdalus). As mudas utilizadas eran provenientes de micropropagação e tinham dois meses quando o experimento foi instalado. As mesmas foram cultivadas em recipientes chamados "rhizoboxes" constituídos por bandas de suporte de PVC e paredes laterais de policarbonato transparentes, posibilitando a observação do crescimento das raízes e a coleta dos exsudatos radiculares. Para evitar a entrada de luz na rizosfera, e a oxidação das raízes, cobriu-se as mesmas com plástico preto.

Utilizou-se como substrato solo oriundo de pomar de pessegueiro. Em cada rhizobox introduziu-se $1,4 \mathrm{~kg}$ de substrato. De acordó com a análise do solo 0 mesmo continha materia orgânica alta $(3,41 \%)$, fósforo assimilável muito alto (43ppm), potássio trocável muito alto (239 ppm), potássio não trocável 287 ppm, sódio normal $(51 \mathrm{ppm})$, magnésio trocável médio-alto (315ppm), cálcio trocável normal, (4218ppm) e relação C/N normal (64\%).

Realizou-se uma primeira irrigação com $375 \mathrm{~mL}$ de água destilada em cada rhizobox logo após o plantio das mudas. Nos dias consecutivos nebulizou-se as folhas uma vez ao dia.

Durante a primeira semana a posição das rhizoboxes foi mantida na vertical, para permitir 0 crescimento normal das mudas. Posteriormente, as mesmas foram inclinadas para estimular 0 crescimento das raízes.

A temperatura média da casa de vegetação foi de $27^{\circ} \mathrm{C}$, a umidade relativa em torno de $65 \%$ e 0 fotoperíodo de 16 horas.

A cada aplicação de $\mathrm{N}$ (na forma de ureia), forneceu-se $100 \mathrm{~mL}$ de solução nitrogenada ( $8 \mathrm{mM}$ de N) por rhizobox a segunda semana do plantio das mudas. As plantas que não receberam a solução nitrogenada, receberam água destilada na mesma proporção.

\section{Análises realizadas:}

Intensidade de verde da folha: através do aparelho SPAD Minolta, realizou-se duas medidas para cada lâmina foliar de três folhas por planta, a partir da primeira folha jovem expandida. Esta análise foi realizada a cada aplicação de $\mathrm{N}$ realizada.

Número médio de folhas por muda: através da contagem do número de folhas de cada muda no primeiro e último dias do experimento.

Altura média da parte aérea: obtido através da média do comprimento em $\mathrm{cm}$, no primeiro e último dias do experimento.

Massa fresca da raíz e da parte aérea das mudas: no último dia do experimento as plantas foram retiradas das rhizoboxes, separadas em parte aérea e raiz e pesadas em balança analítica (Gilbertini TM 1600).

Massa seca da raiz e da parte aérea: após secagem em estufa a $65^{\circ} \mathrm{C}$ por $72 \mathrm{~h}$, pesou-se o material vegetal embalança analítica (Gilbertini TM 1600);

Composição e quantificação de ácidos orgânicos de exsudatos radiculares: As coletas de exsudatos foram realizadas duas vezes por semana, sempre um dia após o tratamento (fornecimento da solução nitrogenada), conforme metodología de Neumann et al. (2014), totalizando cinco coletas de exsudatos radiculares. Para obter-se os exsudatos da rizhosfera in situ, após a abertura das rhizoboxes, colocou-se sobre as raízes brancas discos de papel de filtro absorvente (Whatman $n^{0} 3$ ) com $5 \mathrm{~mm}$ de diâmetro, previamente lavados em solução de águá milliQ + metanol na proporção de 3:1 e secados em capela e fluxo laminar.

Estes discos de papel imediatamente após serem colocados sobre as raízes foram umedecidos 
com agua milliQ, objetivando a indução do fluxo de exsudados radiculares em relaçãoao papel. As paredes das rhizoboxes eram fechadas para garantir o contato entre o papel e as raízes. Depois de uma hora, recolhiase os discos de papel com auxílio de pinça e transferiase os mesmos para eppendorfs de $2 \mathrm{~mL}$ onde eran acrescidos $1 \mathrm{~mL}$ de agua milliQ por eppendorf.

As amostras coletadas foram congeladas a $-20^{\circ} \mathrm{C}$ até o momento da análise, quand oforam filtradas em filtros de nylon $(0,45 \mu \mathrm{m})$. Os ácidos orgánicos foram quantificados por cromatografia líquida de alto desempenho com colunaLiChrospher5 $\mu \mathrm{m}, \mathrm{RP}-18 \mathrm{uM}$ (Supelco, Inc., Bellefonte, PA, EUA). O tampão de eluição utilizado foi de $18 \mathrm{mmol} / \mathrm{L}$ de $\mathrm{KH}_{2} \mathrm{PO}_{4}$, com $\mathrm{pH}$ 2,1 ajustado com $\mathrm{H}_{3} \mathrm{PO}_{4}$. Os cromatogramasforam corridos durante 40 min e o comprimento de onda de detecção foi de $210 \mathrm{~nm}$. Os ácidos orgánicos foram identificados e quantificados conforme Neumann et al. (2014).

Análise de ácidos orgânicos presentes na seiva das mudas:

Para a coleta da seiva do xilema, o sistema radicular de cada planta foi colocado em uma câmara de pressão Scholander. O caule foi cortado $20 \mathrm{~cm}$ acima da inserção das principais raízes laterais, alguns centímetros de casca foram removidos no final do corte para evitar a contaminação com a seiva do floema, e uma pressão de $0,3 \mathrm{MPa}$, foi então aplicada ao sistema radicular. Aproximadamente 500-3000ul de seiva por planta foram coletados em eppendorfs. Após a coleta, as amostras foram congeladas a $-20^{\circ} \mathrm{C}$ até o momento da injeção em HPLC. Duas horas antes da análise as amostras foram retiradas do congelador e filtradas em filtro de nylon $(0,20 \mu m)$ e diluídas em água milliQ já que o material coletado era inferior a $1 \mathrm{~mL}$ por amostra, ou seja era acrescida água até a amostra atingir $1 \mathrm{~mL}$. A análise foi realizada de acordo com metodologia de Newmanet et al., (2013). Os ácidos orgânicos da seiva do xilema foram quantificados em HPLC com uma coluna de $300 \times 7,8$ milímetros Aminex de troca iônica (HPX-87H, Bio-Rad, Hercules, CA) conforme descrito por López-Millánet et al., (2000).

\section{Análise de ácidos orgânicos presentes na raiz das mudas:}

Ao final do experimento coletou-se raízes brancas, as quais foram lavadas em água destilada e posteriormente congeladas a $-20^{\circ} \mathrm{C}$ até o momento de serem preparadas para injeção em HPLC. Cada amostra foi pesada em balança analítica e posteriormente adicionou-se $1,5 \mathrm{~mL}$ de solução de ácido fosfórico a $5 \%$, misturando-se até que as mesmas se transform em um líquido uniforme. Então as amostras foram centrifugadas por 10 minutos, a $3^{\circ} \mathrm{C}$ e $10.000 \mathrm{G}$. Posteriormente foi realizada a filtragem com filtro de nylon de $(0,20 \mu \mathrm{m})$ e então foi realizada a injeção em HPLC.

Separação do ácido oxálico do nitrato:

$0,1 \mathrm{~g}$ de hidroxyapatita (hidrofosfato de cálcio), $4 \mathrm{~mL}$ de solução ácida $\left(\mathrm{H}_{2} \mathrm{SO}_{4} 85 \%\right.$ a pH 2,5) e $1 \mathrm{~mL}$ da amostra foram adicionados a tubos de falcon e misturados, a 129 rpm por 60 minutos. Entãocentrifugouse por 10 minutos a $30000 \mathrm{rpm}$ em temperatura ambiente $\left(20^{\circ} \mathrm{C}\right)$. Coletou-se o sobrenadante, contendo o nitrato. Filtrou-se (filtros de nylon $0,45 \mu \mathrm{m}$ ) e injetouse em HPLC, possibilitando assim quantificar o nitrato presente nas amostras, pois o cálcio rompe a ligação com $\mathrm{N}$ e se liga ao oxalato. Ao material restante nos tubos falcons (hidroxiapatita) adicionou-se $5 \mathrm{~mL}$ de solução $0.1 \mathrm{~mol} / \mathrm{L}\left(\mathrm{NH}_{4}\right) 2 \mathrm{HPO}_{4} \mathrm{~K}_{2} \mathrm{HPO}_{4}$ a pH 8,5. Esta solução foi misturada por 120 minutos quando foi então centrifugada por 10 minutos a $20^{\circ} \mathrm{C}$ e a $30000 \mathrm{rpm}$. Após isso, coletou-se o sobrenadante, filtrou-se (filtro de $0,45 \mu \mathrm{m})$ e injetou-se as amostras em HPLC para determinar 0 ácido oxálico presente nas mesmas.

0 delineamento adotado foi inteiramente casualizado, em um fatorial $2 \times 2$, ou seja, duas doses de $\mathrm{N}(0$ e $8 \mathrm{mM})$ e dois genótipos de porta enxerto Prunus ('GF 677' e 'GxN15'), sendo os tratamentos compostos pela combinação entre estes fatores. A parcela experimental foi composta por 10 plantas, totalizando 40 plantas no experimento).

Os dados foram submetidos à análise de variância pelo teste F. Quando o efeito de tratamento foi significativo, realizou-se o teste de Tukey ao nível de $5 \%$ de probabilidade de erro. As análises estatísticas foram realizadas com o emprego do programa SISVAR versão 5.1 (Ferreira, 2011).

\section{RESULTADOS E DISCUSSÃO}

$\mathrm{Na}$ data do plantio o genótipo 'GF 677' apresentou índice de clorofila 38,46, altura média das mudas de $17,20 \mathrm{~cm}$ e número médio de folhas foi 7 . O genotipo 'G×N15' apresentou índice Spad 34,88, 
comprimento das mudas de $16,82 \mathrm{~cm}$ e 8 folhas, em média.Na primeira data de avaliação (26/05/2015), já observou-se diferença entre os genótipos, sendo o ' $\mathrm{G} \times \mathrm{N} 15$ ' o que apresentou maior comprimento da parte aérea e maior número de folhas e menor número de gemas por $\mathrm{cm}$ de ramo (Tabela 1). Nesta data as plantas ainda não tinham começado a receber fertilização nitrogenada. Nas demais datas avaliadas este comportamento foi o mesmo, caracterizando maior vigor do 'G×N15' em relação ao 'GF 677'.

Tabela 1: Altura de planta, número de folhas, número de gemas por $\mathrm{cm}$ e índice Spad de mudas de portaenxertos de pessegueiro 'G× N15'e 'GF 677' com e sem fertilização nitrogenada em diferentes datas (26/05, 03/06, 09/06 e 16/06/2015). UNIBO, Cesena, FC, 2017.

\begin{tabular}{|c|c|c|c|c|}
\hline \multicolumn{5}{|l|}{$26 / 05 / 2015$} \\
\hline Genótipo & Altura de planta (cm) & Número de folhas & $\mathrm{N}^{\circ}$ de gemas $(\mathrm{cm})$ & Índice Spad \\
\hline 'G×N15' & $20,80 \mathrm{a}$ & $11,00 \mathrm{a}$ & $1,89 \mathrm{~b}$ & $39,05 \mathrm{~ns}$ \\
\hline 'GF677' & $17,68 \mathrm{~b}$ & $8,00 \mathrm{~b}$ & $2,24 \mathrm{a}$ & 40,33 \\
\hline CV(\%) ${ }^{1}$ & 10,10 & 15,31 & 11,58 & 7,50 \\
\hline \multicolumn{5}{|l|}{$03 / 06 / 21015$} \\
\hline 'G×N15' & $22,42 \mathrm{a}$ & 9,40 a & $2,00 \mathrm{~b}$ & $41,39 \mathrm{~b}$ \\
\hline 'GF677' & $18,87 \mathrm{~b}$ & $6,84 \mathrm{~b}$ & $3,00 \mathrm{a}$ & $75,29 a$ \\
\hline \multicolumn{5}{|c|}{ Tratamento } \\
\hline Com N & 20,63 ns & $7,89 \mathrm{~ns}$ & $2,68 \mathrm{~ns}$ & $44,45 \mathrm{a}$ \\
\hline Sem N & 20,75 & 8,40 & 2,52 & $42,13 \mathrm{~b}$ \\
\hline CV(\%) ${ }^{1}$ & 9,33 & 14,34 & 12,15 & 6,21 \\
\hline \multicolumn{5}{|l|}{$09 / 06 / 21015$} \\
\hline 'G×N15' & $22,62 \mathrm{a}$ & 9,00 a & $2,47 \mathrm{~ns}$ & $40,20 \mathrm{~b}$ \\
\hline 'GF677’ & $19,16 \mathrm{~b}$ & $7,00 \mathrm{~b}$ & 2,68 & $46,52 \mathrm{a}$ \\
\hline \multicolumn{5}{|c|}{ Tratamento } \\
\hline Com N & $21,10 \mathrm{~ns}$ & $8,00 \mathrm{~ns}$ & $2,65 \mathrm{~ns}$ & $47,58 \mathrm{a}$ \\
\hline Sem N & 20,77 & 8,50 & 2,49 & $45,47 \mathrm{~b}$ \\
\hline CV(\%) ${ }^{1}$ & 13,25 & 13,54 & 14,63 & 13,25 \\
\hline \multicolumn{5}{|l|}{$16 / 06 / 21015$} \\
\hline 'G×N15' & $23,35 \mathrm{a}$ & $9,60 \mathrm{a}$ & $2,44 \mathrm{~ns}$ & $43,71 b$ \\
\hline 'GF677' & $19,42 b$ & $7,95 \mathrm{~b}$ & 2,46 & $48,44 \mathrm{a}$ \\
\hline \multicolumn{5}{|c|}{ Tratamento } \\
\hline Com N & $21,39 \mathrm{~ns}$ & $8,84 \mathrm{~ns}$ & $2,45 \mathrm{~ns}$ & $47,01 \mathrm{a}$ \\
\hline Sem N & 21,47 & 8,75 & 2,46 & $45,07 \mathrm{~b}$ \\
\hline CV(\%) ${ }^{1}$ & 9,11 & 11,77 & 10,18 & 6,41 \\
\hline
\end{tabular}

*Médias seguidas por letras distintas, minúsculas na coluna, diferem entre si pelo Teste de Tukey a $5 \%$ de probabilidade de erro. *ns (não significativo) a $5 \%$ de probabilidade de erro. ${ }^{1}$ C.V.(\%) Coeficiente de variação.

Não houve interação entre os fatores testados para nenhuma das variáveis.

Altura de planta, número de folhas e número de gemas não foram influenciadas pelo $\mathrm{N}$ aplicado (Tabela 1). Estes dados contrariam Souza et al. (2015) os quais observaram efeito do $\mathrm{N}$ em portaenxerto de goiabeira Crioula para altura de plantas e número de folhas, sendo que a adubação nitrogenada nas doses de 70, 130 e $160 \%$ de $N$ da dose recomendada para a cultura promoveram efeito linear e decrescente. Os mesmos autores verificaram redução de 5,10\%na altura de plantas com aumento de $30 \%$ das doses de N. Cantarella (2007) e Sousa et al. (2007) afirmam que o aumento da adubação com fertilizantes nitrogenados podem levar a acidificação do meio, reduzindo a disponibilidade de nutrientes às plantas.
Não foi observado efeito da fertilização nitrogenada no índice Spad das folhas. Verificou-se efeito apenas do genótipo, sendo que o portaenxerto 'GF 677' destacouse com o maior valor em todas as datas avaliadas. Estes resultados são contrários aos obtidos por Sotomayor et al., (2014) os quais não observaram diferença significativa em relação à leitura SPAD das folhas desses dois genótipos em condições de solo calcário. A que se poderia atribuir essa diferença de comportamento?

A massa seca de mudas tem grande importância como indicativo da qualidade, pois reflete o crescimento destas em função da quantidade de nutrientes absorvidos (Franco et al., 2007). As variáveis massa seca da raiz e da parte aérea não foram afetadas pelos fatores em estudo (Tabela 2), indicando que a dose de $\mathrm{N}$ fornecida às plantas provavelmente tenha sido insuficiente para estimular o crescimento vegetativo. 
Tabela 2: Massa seca de raiz de mudas de portaenxertos de pessegueiro 'G×N15'e 'GF 677' com e sem fertilização nitrogenada. 16/06/21015. UNIBO, Cesena, FC, 2017.

\begin{tabular}{lll}
\hline Genótipo & Massa seca da raiz $\mathbf{( g )}$ & Massa seca da parte aérea $\mathbf{( g )}$ \\
\hline 'G× N15' & $0,67 \mathrm{~ns}$ & $1,17 \mathrm{~ns}$ \\
'GF 677 ' & 0,78 & 1,13 \\
\hline Tratamento & & \\
\hline Com N & $0,69 \mathrm{~ns}$ & $1,16 \mathrm{~ns}$ \\
Sem N & 0,76 & 1,14 \\
\hline CV(\%) & $\mathbf{3 1 , 4 2}$ & $\mathbf{1 3 , 2 2}$ \\
\hline
\end{tabular}

*ns (não significativo) teste de tukey ao nível de 5\% de probabilidade de erro. ${ }^{1}$ C.V.(\%) Coeficiente de variação.

Embora não tenha sido observada diferença significativa em virtude da fertilização nitrogenada, as mudas não apresentaram sintomas de deficiência de $\mathrm{N}$.
Os principais ácidos orgânicos detectados nos exsudatos radiculares dos portaenxertos 'GF 677' e 'Gx N15' foram: oxálico, nitrato, tartárico, málico e fumárico (Tabela 3).

Tabela 3: Concentração de ácidos orgânicos $\left(u m o l \mathrm{~cm}^{-1}\right)$ coletados em cinco datas distintas de exudados radiculares de mudas de portaenxertos de pessegueiro 'G× N15' e 'GF 677' com e sem fertilização nitrogenada, obtidos pelo uso da cromatografia líquida de alto desempenho (HPLC). UNIBO, Cesena, FC, 2017.

\begin{tabular}{|c|c|c|c|c|c|}
\hline \multicolumn{6}{|c|}{$1^{\text {a }}$ coleta $(27 / 05 / 2015)$} \\
\hline & Oxálico & Nitrato & Tartárico & Málico & Fumárico \\
\hline \multicolumn{6}{|l|}{ Genótipo } \\
\hline 'Gx N15' & $0,0123 \mathrm{~b}$ & $0,0152 \mathrm{~b}$ & $0,0017 \mathrm{~ns}$ & - & - \\
\hline 'GF 677' & $0,0360 \mathrm{a}$ & $0,0395 a$ & 0,0020 & - & - \\
\hline Tratamento & & & & - & - \\
\hline Com N & $0,015873 \mathrm{~b}$ & $0,0189 \mathrm{~b}$ & $0,0017 \mathrm{~ns}$ & - & - \\
\hline Sem N & $0,032539 a$ & $0,0358 \mathrm{a}$ & 0,0021 & - & - \\
\hline C.V. $(\%)^{1}$ & 39,73 & 39,73 & 21,43 & - & - \\
\hline \multicolumn{6}{|c|}{$2^{a}$ coleta $(29 / 05 / 2015)$} \\
\hline Genótipo & & & & - & - \\
\hline 'Gx N15' & $0,1519 \mathrm{~ns}$ & $0,3363 \mathrm{~ns}$ & $0,000026 \mathrm{~b}$ & - & - \\
\hline 'GF 677’ & 0,1398 & 0,3760 & $0,000035 a$ & - & - \\
\hline Tratamento & & & & - & - \\
\hline Com N & $0,2125 a$ & $0,5239 a$ & $0,000029 \mathrm{~ns}$ & - & - \\
\hline Sem N & $0,0792 \mathrm{~b}$ & $0,1884 \mathrm{~b}$ & 0,000033 & - & - \\
\hline C.V. $(\%)^{1}$ & 18,56 & 19,08 & 20,63 & & \\
\hline \multicolumn{6}{|c|}{$3^{a}$ coleta $(04 / 06 / 2015)$} \\
\hline \multicolumn{6}{|l|}{ Genótipo } \\
\hline 'Gx N15’ & $0,2127 \mathrm{~ns}$ & $0,2246 \mathrm{~ns}$ & $0,0037 \mathrm{~ns}$ & 0,0205 ns & $0,000020 \mathrm{~b}$ \\
\hline 'GF 677' & 0,1577 & 0,1858 & 0,0043 & 0,0138 & $0,000047 \mathrm{a}$ \\
\hline \multicolumn{6}{|l|}{ Tratamento } \\
\hline Com N & $0,2591 \mathrm{a}$ & $0,2733 a$ & $0,0033 \mathrm{~ns}$ & $0,0220 \mathrm{~ns}$ & $0,000020 \mathrm{~ns}$ \\
\hline Sem N & $0,1113 b$ & $0,1372 b$ & 0,0047 & 0,1227 & 0,000039 \\
\hline C.V. $(\%)^{1}$ & 41,41 & 43,85 & 30,37 & 52,06 & 40,39 \\
\hline \multicolumn{6}{|c|}{$4^{a}$ coleta $(10 / 06 / 2015)$} \\
\hline \multicolumn{6}{|l|}{ Genótipo } \\
\hline 'Gx N15' & $0,1927 \mathrm{~ns}$ & $0,2035 \mathrm{~ns}$ & $0,0064 \mathrm{~ns}$ & 0,0072 ns & $0,000060 \mathrm{~ns}$ \\
\hline 'GF 677' & 0,2449 & 0,2586 & 0,0066 & 0,0105 & 0,000064 \\
\hline \multicolumn{6}{|l|}{ Tratamento } \\
\hline Com N & $0,2293 \mathrm{~ns}$ & $0,2200 \mathrm{~ns}$ & 0,0059 & $0,1142 \mathrm{~ns}$ & $0,000058 \mathrm{~ns}$ \\
\hline Sem N & 0,2084 & 0,2421 & 0,0070 & 0,0063 & 0,000070 \\
\hline C.V. $(\%)^{1}$ & 45,41 & 45,41 & 27,02 & 45,86 & 63,70 \\
\hline \multicolumn{6}{|c|}{$5^{a}$ coleta $(17 / 06 / 2015)$} \\
\hline \multicolumn{6}{|l|}{ Genótipo } \\
\hline 'Gx N15’' & $0,0902 \mathrm{~b}$ & $0,0952 \mathrm{~b}$ & $0,0041 \mathrm{~ns}$ & $0,0045 \mathrm{~ns}$ & $0,000020 \mathrm{~b}$ \\
\hline 'GF 677' & $0,2517 a$ & $0,2658 \mathrm{a}$ & 0,0046 & 0,0039 & $0,000047 a$ \\
\hline \multicolumn{6}{|l|}{ Tratamento } \\
\hline Com N & $0,1736 \mathrm{~ns}$ & $0,1833 \mathrm{~ns}$ & $0,0041 \mathrm{~ns}$ & $0,0045 \mathrm{~ns}$ & $0,000028 \mathrm{~ns}$ \\
\hline Sem N & 0,1683 & 0,1777 & 0,0046 & 0,0039 & 0,000039 \\
\hline C.V. $(\%)^{1}$ & 38,84 & 38,84 & 23,06 & 40,91 & 40,39 \\
\hline
\end{tabular}

*Médias seguidas por letras distintas, minúsculas na coluna, diferem entre si pelo Teste de Tukey a $5 \%$ de probabilidade de erro. ${ }^{*}$ ns (não significativo) a $5 \%$ de probabilidade de erro. ${ }^{1}$ C.V.(\%) Coeficiente de variação. 